\section{Síndrome de Titono}

\section{Tithonus syndrome}

Un hombre trabajado por el tiempo, un hombre que ni siquiera espera la muerte (las pruebas de la muerte son estadísticas y nadie hay que no corra el albur de ser el primer inmortal), fragmento del poema "Alguien"

Jorge Luis Borges (1899-1986)

\section{Sr. Editor:}

Titono, en la mitología griega, era un mortal, hijo de Laomedonte rey de Troya, siendo de una belleza deslumbrante conquistó el corazón de la diosa Eos, Aurora en la mitología latina (Figura 1). Esta le pidió a Zeus la inmortalidad para su amado, cosa que le fue concedida. Pero la diosa no pidió la juventud eterna, de modo que Titono fue haciéndose cada vez más anciano, hasta que se convirtió en grillo. Desde entonces cada vez que Eos se despierta por la mañana y llora produciendo el rocío con sus lágrimas, Titono se alimenta de las mismas, mientras susurra el reconocido sonido con el que pide su muerte a Tánatos, el hijo de la noche ${ }^{1,2}$.

Titono y Eos tuvieron dos hijos, Memnón, rey de Etiopía, y Ematión. En el Himno homérico a Afrodita, la diosa cuenta a Anquises la miserable vejez de Titono. El mito es evocado en un poema de Safo de Mitilene (650-580 a. C.). La etimología de Titono es quizá de

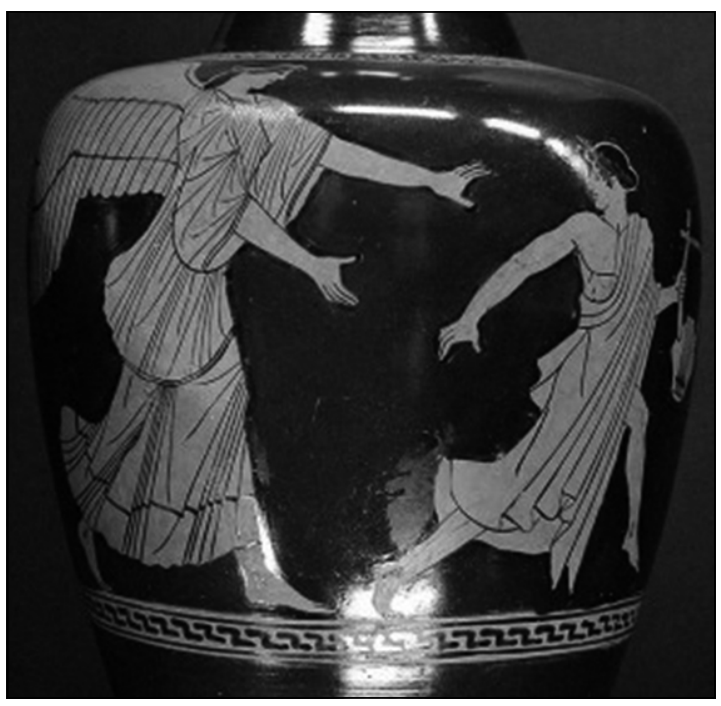

Figura 1. Eos persiguiendo a Titono. Jarra de vino de cerámica, circa 470 a 460 a. C. Colección Canino, Museo del Louvre, París, Francia. En: http://olympia.over-blog.es/ article-titono-40922533.html; consultado el 13/4/17.

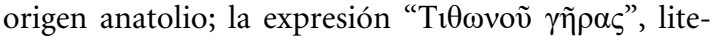
ralmente "una vejez de Titón" designa una vida que se eterniza ${ }^{1,3,4}$.

Recientemente Skolnik denominó síndrome de Titono a la situación que surge, seguramente fruto del amor, en donde presos del egoísmo y con la necesidad de retener para siempre a nuestros seres queridos nos aferramos a esos cuerpos que se van desdibujando y se convierten solo en la cascara de quienes supimos amar. El deseo de la inmortalidad condena a veces a largas agonías, plagadas de maniobras invasivas, desproporcionadas que ya ni siquiera cuentan con el consentimiento de los propios pacientes 5 . Al igual que Titono, no puede hablar, comer, o moverse estando atrapado en su propio cuerpo, tal vez incluso deseando nos demos por vencidos y los acompañemos a una muerte digna y sin padecimientos. Ya hablaba San Juan Pablo II de la sana aceptación de la condición humana ante la muerte.

Los antiguos griegos sabían, nos avisaban que la mayoría de los deseos son incompletos. Tenemos una limitada capacidad de prevenir, y mucho menos de comprender que es lo que verdaderamente necesitamos y queremos. En la era actual, nos hemos esforzado por entender los misterios del corazón, las complejidades del riñón, y las áreas ocultas del cerebro entre otros. Hemos hecho lo mejor para curar el cuerpo cuando se enferma, y extender nuestro tiempo en la tierra. Nos hemos involucrado en una batalla que sabemos nunca vamos a ganar $y$ por esto, tenemos que afrontar lo que significa perder a aquellos cercanos a nosotros, a través de la lenta comprensión de las consecuencias de decisiones que tomamos en cada oportunidad. Cada elección es bien intencionada, hasta que vemos a alguien que amamos, yaciendo en frente nuestro, sin saber que estamos allí.

Los pacientes que padecen de este síndrome, al decir del Dr. Daniel Flichtentrei en el contexto de la muerte digna "son una nueva categoría de pacientes. Una que incluye a familias destrozadas. A madres presas de esperanzas sin fundamento. A hijos extenuados e insomnes velando a sus padres que no acaban de morir. Desde sus ojos ausentes, una mirada vacía nos señala como un dedo acusador. Allí están, aunque nadie los vea. Detenidos en un camino que no conduce a ninguna parte. Vegetativos, comatosos, alimentados por el largo ombligo del soporte vital. Arrullados por el soplido incesante de los respiradores. Una vez más el sueño de la razón produjo monstruos encarnizados. ¡Despertate! Le susurran sus madres al oído mientras les cantan nanas de la infancia (...) pero ellos no se despiertan porque no están dormidos"6.

Pablo Young, Mariano Demuria, Bárbara C. Finn, Julio E. Bruetman Servicio de Clínica Médica, Hospital Británico de Buenos Aires, Argentina. 


\section{Referencias}

1. Loewi AM. La invasión pacífica de los longevos. En: Inmortalidad. Promesas, fantasías y realidades de la eterna juventud. Autoría editores, Buenos Aires: 2017, p 25-41.

2. Miller WT. Tithonus. Semin Roentgenol 1994; 29: 317.

3. de Grey AD. Combating the Tithonus error: what works? Rejuvenation Res 2008; 11: 713-5.

4. Weissmann G. Tithonus and the fruit fly: new science and old myths. FASEB J 2008; 22: 1619-22.
5. Skolnik N. Tithonus Syndrome. JAMA Intern Med 2016; 176: 1247.

6. Flichtentrei D. Permiso para morir. Cuando el fin no encuentra su final. IntraMed editores, Buenos Aires: 2013, p 11-3.

Correspondencia a:

Pablo Young

Hospital Británico. Perdriel 74 (1280) Buenos Aires, Argentina. pabloyoung2003@yahoo.com.ar 